\title{
ASPECTOS DA SINTAXE DE CLÍTICOS E ARTIGOS EM PORTUGUÊS*
}

\author{
Heloisa Maria Moreira Lima Salles **
}

\section{Introdução}

$\mathbf{N}$ este estudo, examina-se a sintaxe de clíticos e artigos em português (e demais línguas românicas), considerando-se particularmente a hipótese de que a presença da contração entre a preposição e o artigo definido se correlaciona com a presença de clíticos pronominais no sistema lingüístico. Adotando o quadro teórico da gramática gerativa, em particular o programa minimalista de pesquisa (cf. Chomsky 1995; 1998), a análise demonstra que o fenômeno da contração entre a preposição e o artigo [P+art] tem um correlato sintático. Essa demonstração se faz pelo exame da extração do sintagma determinante introduzido por preposição em construções QU (interrogativas e relativas), em que se verifica o carreamento obrigatório da preposição em portu-

* Uma parte da presente análise foi desenvolvida durante meu doutorado na Universidade do País de Gales (University of Wales), sob a orientação do Professor Doutor Ian Roberts, a quem gostaria de agradecer pelo apoio e pelas discussões, que em muito enriqueceram a análise e minha formação acadêmica. Agradeço também a Anna Roussou, Bob Borsley, Joseph Emonds, bem como à audiência do $4^{*}$ Encontro do Celsul, onde a presente análise foi apresentada. Os equívocos são de minha inteira responsabilidade.

** Universidade de Brasnlia. 
guês, mas não em inglês. Considerando que clíticos têm sido analisados como a realização de traços-phi (isto é, traços de pessoa, gênero e número) em categorias funcionais, propõe-se uma correlação entre a presença de clíticos no sistema gramatical e a ocorrência da contração [P+art], analisada como a realização de traços-phi em núcleos preposicionais.

A discussão será desenvolvida como a seguir. Na próxima seção, será feita uma exposição acerca das implicações sintáticas da realização de traços-phi em núcleos preposicionais, considerando-se particularmente o contraste entre o português e o inglês na extração do DP introduzido por $\mathrm{P}$ em construções-QU (interrogativas e relativas); na primeira sub-seção, será proposto que a contração [P+art] é a expressão morfofonológica da operação Agree, que permite a eliminação de traços formais phi não-interpretáveis no núcleo preposicional (funcional); na seção seguinte, será considerado o desenvolvimento diacrônico de clíticos e artigos em português, apontando-se a origem comum e o fato de que compartilham a propriedade de poderem se cliticizar a um núcleo. Na conclusão, serão apontadas as implicações desse estudo para a identificação de artigos e clíticos como a categoria funcional Determinante, bem como para o estudo da variação paramétrica no que se refere às propriedades dessa categoria funcional.

\section{O caráter sintático da contração entre a preposição e o artigo em português: evidência a partir da extração de sintagma determinante (DP) introduzido por preposição em construções QU}

Um aspecto interessante da sintaxe das preposições em português é o fato de, em construções-QU, a preposição ser carreada com a palavra-QU para, o início da oração (especificamente, para a posição de especificador do sintagma complementador/CP), isto é, a preposição não pode ficar órfã, conforme ilustrado em (1a)e (1b):

1 Cabe destacar que no português do Brasil são encontradas ainda: (a) a chamada relativa cortadora, com apagamento de $\mathrm{P}$; e (b) a relativa com o pronome lembrete (cf. Tarallo (1983)):

(i) A pessoa que eu preciso chegou.

(ii) A pessoa que eu moro com ela chegou.

É interessante notar que em inglês não é encontrada a construção com o apagamento de $\mathrm{P}$ (i) [The person that I talk *(to)], embora seja possivel a relativa com o pronome lembrete em (ii) (The man who, John saw him. Assim, no português do Brasil, o padrão é oposto: P pode ser apagada, mas não pode ocorrer órfã. Será demonstrado que tais fatos podem ser discutidos em termos da presente análise. 
(1) a. Com quem Maria falou.

a'. A pessoa com quem Maria falou.

b. *Quem Maria falou com.

b'. *A pessoa que Maria falou com.

Em inglês, todavia, são encontradas tanto a construção com a P-órfã, como aquela em que $\mathrm{P}$ é realizada juntamente com a palavra interrogtiva/QU, ${ }^{2}$ ilustradas em (2a) e (2b), respectivamente:

(2) a. Who did Mary talk to.

a'. The person (that) Mary talked to.

b. To whom did Mary talk.

b'. The person to whom Mary talked.

Conforme ressaltado em Riemsdijk (1978), a ocorrência de P-órfã é uma opção marcada entre as línguas, cabendo indagar a razão da escassez do fenômeno. Entre as línguas indo-européias, é encontrada no grupo germânico: além do inglês, nas línguas escandinavas, e de forma restrita, no holandês e no alemão. Esse fenômeno tem sido amplamente discutido na literatura gerativa (Riemsdijk, 1978; Hornstein; Weinberg, 1981; Kayne, 1984; Radford, 1997; Salles, 1997; Law, 1998, entre outros).

Um aspecto recorrente em algumas análises é considerar que a possibilidade de deixar a preposição órfã decorre da formação de um complexo na sintaxe entre o verbo e a preposição - a reanálise $[\mathrm{V}+\mathrm{P}]$. Um problema é que a própria noção de reanálise entre $\mathrm{V}$ e $\mathrm{P}$ tem sido questionada: conforme observado em Baltin e Postal (1996), existem evidências de que o elemento na posição de objeto do complexo $[\mathrm{V}+\mathrm{P}]$ não se comporta como um DP independente, mas antes como um objeto PP.

Por exemplo, existe uma assimetria no comportamento sintático do DP objeto e do PP objeto (notada em Ross, 1967, citada em Baltin e Postal, 1996), a qual não seria de se esperar em face da reanálise: conforme ilustrado em (3), o DP na posição de objeto de $V$, mas não na posição de objeto de $P$, pode sofrer deslocamento como DP pesado (Heavy-NP shift):

(3) a. I discussed $t_{\text {the problems...] }}$ with Lorenzo the problems he was having ... b. *I argued with $t_{[\text {the driver's...] }}$ about such problems the driver's union leader

2 Há que se ressaltar que, no inglês moderno vernacular, a construção com a preposição órfã é nitidamente preferida. 
SALLES, H. M. M. L. Aspectos da sintaxe de clíticos...

A mesma assimetria é observada em construções envolvendo lacuna (gapping), ilustradas em (4): ${ }^{3}$

(4) a. Frank called Sandra and Arthur Louise.

b. Frank talked to Sandra and Arthur *(to) Louise.

Tais considerações levam a crer que a hipótese da reanálise $[\mathrm{V}+\mathrm{P}]$ não se aplica aos contextos de P-órfă, o que enfraquece seu poder explicativo. Salles (1997), por sua vez, sugere que a questão não é por que em algumas línguas a preposição pode ficar órfã, mas sim por que tem de ser alçada obrigatoriamente junto com a palavra QU, em línguas como o português [cf. (1)]. Nesse sentido, focaliza a atenção na relação entre a preposição e o determinante (P e D) (ver também Law, 1998).

Em termos minimalistas, pode-se dizer que tanto em português como em inglês, a categoria $\mathrm{C}$ tem um traço EPP, do que decorre o alçamento obrigatório da palavra QU para specCP. No sistema de Chomsky (1998; 1999), o traço EPP cria a posição de especificador. Em português (e demais línguas românicas), porém, se a palavra QU é extraída do sintagma preposicional, a preposição é obrigatoriamente carreada (o chamado pied piping generalizado). Em inglês, o carreamento da preposição é opcional. As derivações em português e em inglês estão ilustradas em (5a) e (5b/b'), respectivamente:

(5) a. $l_{\mathrm{CP}}$ com quem (que) $\left[_{\mathrm{IP}}\right.$ Maria $\left[_{\mathrm{I}}\right.$, falou $\left[_{\mathrm{VP}}\right.$ Maria $\left[\right.$ fatou $\left[_{\mathrm{VP}}\left[_{\mathrm{PP}}\right.\right.$ com $\left(_{\mathrm{DP}}\right.$ quem )]]]]\}

b. $\left[_{\mathrm{CP}}\right.$ who did $\left[_{\mathrm{PP}} \operatorname{Mary}\left[{ }_{\mathrm{I}}\right.\right.$, talk $\left[_{\mathrm{VP}}\right.$ Maria ffatou $\left[{ }_{\mathrm{VP}}\left[{ }_{\mathrm{PP}}\right.\right.$ to $\left[{ }_{\mathrm{DP}}\right.$ whe $\left.\left.\left.\left.\left.]\right]\right]\right]\right]\right]$

b'. $\left\{_{\mathrm{CP}}\right.$ To whom did $\left[_{\mathrm{TP}}\right.$ Mary $\left[_{\mathrm{I}}\right.$, talk $\left[_{\mathrm{VP}}\right.$ Maria ffatou $\left[_{\mathrm{VP}}\left[_{\mathrm{PP}}\right.\right.$ to $\left[_{\mathrm{DP}}\right.$ whom ]]]1]\}

Assim, a questão que imediatamente se coloca é por que a preposição é carreada obrigatoriamente com a palavra QU em português. Conforme apontado em Salles (1997), um aspecto interessante da relação entre P e o DP na posição de objeto, em línguas como o português é a contração entre a preposição e o artigo, ilustrado em (6) e (7), do português e do francês.

3 Note-se que mesmo em uma teoria que proíbe movimento à direita (cf. Kayne, 1994), essa observação se mantém: assumindo-se o movimento à esquerda tanto de $V$ quanto de PP, with Lorenzo, a pergunta é por que o complexo [argued+with] não pode se deslocar a esquerda junto com about such problems. 
(6) a. a necessidade $d a(*$ de a) criança.

b. o interesse no/pelo (*em o)/(*per o) assunto.

c. a volta $a o /(* a$ o) Brasil.

(7) a. le besoin des (*de les) enfants.

b. l'intêret $a u$ (*à le) sujet.

b'. le retour aux/ (*à les) Pays Bas.

Salles $(1997 ; 2000)$, propõe que a contração entre a preposição e o artigo é a expressão morfofonológica da formação de um núcleo complexo na sintaxe: $[\mathrm{P}+\mathrm{D}] .{ }^{4} \mathrm{O}$ caráter sintático dessa formação pode ser confirmado com dados do português: em construções infinitivas introduzidas por preposição (com sujeito lexical licenciado pela flexão do infinitivo), a contração [P+art] não ocorre (ou não é obrigatória), conforme ilustrado em (8a-b):

(8) a. A necessidade de as crianças brincarem é clara.

b. $O$ interesse $e m o$ assunto ser discutido é claro.

c. $\left\{_{\mathrm{pp}} \mathrm{P}\left[_{\mathrm{CP}} \mathrm{C}\left[_{\mathrm{IP}}\left({ }_{\mathrm{DP}} \mathrm{DNP}\right) \mathrm{I}\right]\right]\right\}$

Assumindo-se a configuração em (8c) para (8a-b) (cf. Rizzi, 1984; Figueiredo e Silva, 1994), ${ }^{5}$ verifica-se que a contração obrigatória [P+art] só ocorre se $\mathrm{D}$ encontra-se na posição de complemento de $\mathrm{P}$. Inversamente, se D não se encontra na posição de complemento de $\mathrm{P}$, a contração não é obrigatória.

Assim, pode-se dizer que a contração entre a preposição e o artigo tem um correlato sintático, sendo encontrada sempre que as condições morfofonológicas permitirem (o que explica que não seja encontrada com certas preposições, e.g., sobre a). É interessante notar que o caráter sintático da contração é encontrado em outro contexto, a saber a forma wanna(= want to),

4 Adota-se a hipótese DP, segundo a qual NPs são projeçōes máximas de um núcleo funcional D, sendo D o locus da interpretação referencial do NP - o argumento referencial corresponde ao indivíduo (ou o conjunto de indivíduos) denotados pelo NP.

5 Silva (1994), motiva a posição da preposição por meio do contraste em (i). Assumindo que os Casos atribuídos sob regência exigem adjacência linear, demonstra que a interpolação do adverbial entre $\mathrm{P}$ e o DP não é possível se $\mathrm{P}$ atribui caso (oblíquo) ao DP: inversamente, se o DP não recebe caso de $P$ (sendo nominativo), a interpolação é possível:

(i) a. Ele deu o livro pra (amanhã) eu levar.

b. *Ele deu o livro pra (amanhã) mim levar.

A noção de adjacência pode ser discutida em termos da formação do núcleo complexo [P+D]. Na próxima seção, será proposto que o núcleo complexo é formado pela operaçāo Agree (cf. Chomsky, 1999), que licencia traços formais de Caso. 
do inglês. Conforme ilustrado em (9), na presença de uma categoria entre os termos relevantes, a contração não é possível; inversamente, na ausência de um termo interveniente, a contração é possível:

(9) a. who do you want $\mathrm{t}_{\mathrm{wHO}}$ tol *wanna leave?

b. who do you want to/ wanna leave?

No caso da contração $\mathrm{P}+$ art, a posição do sintagma complementador/ $\mathrm{CP})$ dada a formação do núcleo complexo $[\mathrm{P}+\mathrm{D}]$, a palavra $\mathrm{QU}$, ao ser alçada para SpecCP para checar o traço EPP de C, carreia P. Nesse sentido, pode-se formular a generalização de que a impossibilidade de deixar a preposição órfã está condicionada a presença de contração [P+art]. Isso se confirma nas línguas românicas e germânicas, conforme ilustrado na tabela 1:

\begin{tabular}{l|c|c} 
& $\begin{array}{c}+/- \\
\text { P-órfã }\end{array}$ & $\begin{array}{c}=/ \text { - contração } \\
{[\mathrm{P}+\text { art/QU }]}\end{array}$ \\
$\begin{array}{l}\text { Românicas } \\
\text { Alemão }\end{array}$ & - & + \\
Holandês & - & + \\
Inglês & - & + \\
Escandinavas & + & - \\
\hline
\end{tabular}

Cabe então perguntar por que o núcleo complexo $[\mathrm{P}+\mathrm{D}]$ é formado na sintaxe e quais são suas propriedades.

6 A contração entre a preposição e o artigo em alemão é notória, conforme ilustrado em (i) e (ii). Ignora-se o caso restrito de P órfã no alemão - ver Salles $(1997,2000)$ para uma discussão à luz da teoria proposta neste artigo:

(i) as Interesse am /an dem Thema o interesse em- o DAT tema

(ii) die Rückehr zum /zu dem Bahnhof o retorno a-aDAT estação

7 Em holândes, verifica-se a contração entre a preposição e a própria palavra QU. Ignora-se o caso restrito de P órfã no holandês - ver Salles $(1997 ; 2000)$ para uma discussão à luz da teoria proposta neste artigo:

(i) Waarmee snijdt Marjon het vlees?

O que-com corta M. a carne

Com que Marjons corta a carne? 


\section{A contração entre a preposição e o artigo como uma instância da operação Agree}

Uma forma de discutir a idéia de que a contração entre a preposição e o artigo tem um correlato sintático é considerar que o núcleo complexo [P+D] realiza uma versão da operação Agree. A operação Agree se define como um processo de checagem de traços phi não-interpretáveis de um núcleo funcional por traços-phi interpretáveis do nome, com o concomitante apagamento do traço de caso não-interpretável do núcleo nominal (Chomsky, 1998). Assim, Agree constitui um mecanismo de eliminação de traços não interpretáveis (e.g., traços fonológicos, traços phi de T, traço EPP de $\mathrm{T}$ ), os quais são intolerados na interface Lógica ou Fonética. Traços intepretáveis (e.g., traços phi de N) são, por sua vez, acessíveis durante toda a derivação, tendo papel essencial na eliminação dos traços não-interpretáveis.

A idéia de propor a operação Agree no âmbito da projeção PP se apóia na constatação de que existem preposições flexionadas, particularmente na família celta. Em galês, por exemplo, a preposição recebe sufixo de pessoa e número sempre que o complemento da preposição é expresso por uma forma pronominal livre, conforme ilustrado em (10) - [gan 'com' + sufixo número-pessoal] + forma pronominal livre:

(10) a. gennyf fi (1ps)

b. gennyt ti (2ps)

c. ganddo fo (3ps)

d. ganddyn nhw (3ppl)

Assim, pode-se postular uma projeção em camada para $\mathrm{P}$ (PP shell), com um núcleo funcional $p$ selecionando a projeção máxima do núcleo lexical P:9

8 Em irlandês, a preposição flexionada dispensa a presença da forma pronominal livre na posição de objeto de P. Embora o presente estudo esteja voltado para a comparação entre línguas do grupo românico e germânico, vale a pena ressaltar que a correlação entre a presença de traços phi em $\mathrm{P}$ e a possiblidade de deixar a preposição órfã se mantém no grupo celta, visto que as línguas desse grupo não admitem P-órfã. No irlandês, somente a forma flexionada pode ser deixada órfă.

9 A idéia de propor uma estrutura em camada para a projeção de $P$ nāo é nova. Para uma versão, ver Koopman (1993). 


$$
\text { (11)... }\left[_{\mathrm{pP}} \mathrm{p}\left({ }_{\mathrm{pP}} \mathrm{P} X \mathrm{XP}\right)\right]
$$

A operação Agree na projeção $\mathrm{PP}$ pode ter ainda um correlato em $\mathrm{PF}, \mathrm{o}$ qual se manifesta com a presença de um traço EPP em $p$. No sistema de Chomsky (1998), o traço EPP, originalmente associado ao princípio de que toda oração tem um sujeito (Extended Projection Principle), é um traço formal não-interpretável (assim como traços fonológicos, traços phi de T) - a interpretabilidade dos traços formais sendo considerada uma propriedade de L (língua). Sua presença em uma dada categoria funcional está sob variação e sua eliminação é obrigatória, o que pode ser feito no contexto da operação Agree produzindo um efeito de deslocamento de categoria., mais especificamente pela realização da posição de especificador por um XP.

Propõe-se, no presente estudo, que o traço EPP, na projeção PP, pode ser checado de duas formas:

(i) pelo movimento de $\mathrm{D}$ para $p$ (através de $\mathrm{P}$ ), expresso na contração $[\mathrm{P}+\mathrm{art}]$ sempre que as condições morfofonológicas permitirem;

(ii) pelo movimento de DP para specp, produzindo configurações posposicionais, encontradas em alemão e em holandês (línguas que têm também preposições). ${ }^{10}$

Uma conseqüência sintática da operação de checagem do traço EPP por meio de (i) é o carreamento de $P$ em construções QU (cf. (1)). Nesse sentido, em línguas como o inglês, o traço EPP não é encontrado, do que decorre a possibilidade de deixar a preposição órfã em construções QU.

Conforme destacado em Salles (1997), um aspecto essencial para a ocorrência do processo em (i) é a presença de traços phi no artigo definido - assumese que as propriedades de concordância dentro do sintagma nominal garantem que a checagem do traço EPP (bem como dos traços phi não-interpretáveis no núcleo preposicional) seja feita através da categoria $\mathrm{D}$, em particular o artigo. $\mathrm{A}$ presença de traços phi no artigo pode ser vista como uma experiência eliciadora do parâmetro que determina a presença do EPP no núcleo preposicional. Nesse sentido, na ausência de traços phi no artigo, o parâmetro é marcado negativamente (configurando-se a situação default) - é exatamente o que ocorre em inglês.

$10 \mathrm{Um}$ aspecto interessante da sintaxe de PP em alemão e holandês é que a escolha entre pre e posposição é determinada pela intepretação aspectual do predicado (a esse repeito, ver Helmantel, 1997). Assim, a presente análise se aplica naturalmente: em face da presença do traço EPP, a escolha entre o processo (i) e (ii) é condicionada. 
Quanto à contração [P+art], pode-se dizer que se trata da realização de traços phi em $\mathrm{P}$, por cliticização, em condições morfofonológicas específicas. Conforme sugerido em Salles (1997), esse fenômeno pode ser comparado à cliticização pronominal em português e nas demais línguas românicas, se analisado como a realização de traços phi em um núcleo funcional, como tem sido proposto na tradição gerativista. A correlação entre as propriedades dos clíticos objeto e dos artigos será discutida na seção a seguir.

\section{Aspectos da sintaxe de clíticos e artigos em português: evidência da diacronia}

A discussão a respeito da sintaxe de clíticos e artigos em português (e demais línguas românicas) necessariamente remete ao fato de que ambos se originam da mesma categoria em latim, no contexto da perda da morfologia de caso. Além disso, a presença de clíticos e artigos em todas as línguas românicas sugere que o surgimento dessas categorias é relacionado, tendo ocorrido na transição do latim clássico para o proto-românico. Essa identificação, há muito apontada nos estudos gramaticais, tem consequiências teóricas interessantes: no âmbito da gramática gerativa, é particularmente relevante na postulação de categorias funcionais - D(eterminer), $C$ (omplementizer), I(nflection), na medida em que constitui evidência para se atribuir estatuto categorial idêntico a artigos e clíticos, em termos da hipótese DP.

A hipótese DP tem sido amplamente adotada na literatura gerativa: postula que o NP é licenciado na posição de objeto do núcleo funcional $\mathrm{D}$, sendo $\mathrm{D}$ o locus da interpretação referencial do NP - o argumento referencial correspondendo ao indivíduo (ou o conjunto de indivíduos) denotado pelo NP. Conforme destacado em Vincent (1997, p. 151), a maioria das línguas românicas parecem oferecer um argumento particularmente direto em favor dessa hipótese, pelo fato de que existe mais ou menos total sobreposição morfológica nas formas do artigo e dos clíticos objeto. " Esse fenômeno está ilustrado na tabela 2, a seguir, extraída de Vincent (1997, p. 151):

11 Traduzido de: "[...] most of the Romance languages seem to offer a particularly direct argument in favour of the DP hypothesis in that they there is more or less total morphological overlapin the forms of the article and the object clitics." 
SALLES, H. M. M. L. Aspectos da sintaxe de clíticos...

\begin{tabular}{l|c|c|c|c|c}
\cline { 3 - 6 } \multicolumn{2}{c}{} & Masc. sg & Fem. sg & Masc. pl. & Fem. pl. \\
\hline Italiano & artigo & i & la & i & le \\
\hline & clítico & l' & la & l' & le \\
\hline Francês & artigo & le & la & les & les \\
\hline & clítico & le & la & les & les \\
\hline Português & artigo & o & a & os & as \\
\hline & clítico & o & a & os & as \\
\hline
\end{tabular}

No presente estudo, considera-se que essa sobreposição não só reflete a origem comum, como também tem conseqüiências para o licenciamento sintático dessas categorias. Conforme sugerido na seção anterior, as características morfofonológicas de clíticos e artigos em português (e nas demais línguas românicas) têm implicações para o licenciamento do DP.

O desenvolvimento de clíticos e artigos nas línguas românicas é examinado por Vincent $(1997$, p. 149) para quem "os diferentes padrões de realização morfológica dos clíticos de $3^{\mathrm{a}}$. pessoa (os quais sempre se originam de ille, do latim) e dos artigos (originários ora de ille, ora de ipse, do latim) refletem dois desenvolvimentos independentes e convergentes, um envolvendo a relação verbo-objeto e o outro envolvendo a relação oração-sujeito". ${ }^{12}$ Assim, enquanto 0 artigo se origina em sujeitos (pela gramaticalização do tópico, no qual o elemento pronominal ille tem a função original de apontar para um novo item no texto),,$^{13}$ o clítico surge como uma cópia pronominal (um resumptivo), marcando o objeto (por oposição à não marcação do sujeito), em face da perda da morfologia de caso, e em posição pós-verbal, dada a conjugação de dois fatores: a regra existente de colocação do pronome dito fraco,${ }^{14}$ na segunda posição (Wackernagel) e a gramaticalização do movimento do verbo para a primeira posição.

O caráter convergente do desenvolvimento de clíticos e artigos diz respeito à perda das propriedades dêicticas da categoria ille (e ipse) do latim e à retenção do traço de referencialidade. A análise proposta no presente estudo aponta ainda para a convergência em termos da propriedade de realizar traços

12 Traduzido de: "[...] the different patterns of morphological realization of the third-person clitics (which always derive from Latin ille) and articles (sometimes from ille and sometimes from ipse) reflect two independent and convergent developments, one involving the verb-object relation and one the clause-subject relation."

13 A baixa freqüência de formas pronominais $i l l e$ (e ipse) em posição de objeto é considerada por Vincent evidência para situar o desenvolvimento do artigo na posição de sujeito.

14 Adota-se a distinção entre pronomes fortes, fracos e clíticos, conforme formulada em Cardinaletti e Starke (1994). 
phi em um dado núcleo, um fenômeno associado à operação Agree e ao traço EPP. O licenciamento do DP objeto de $\mathrm{P}$ foi discutido na seção anterior, em termos da formação do núcleo complexo $[\mathrm{P}+\mathrm{D}]$, decorrente da presença do traço EPP no núcleo funcional da projeção preposicional, uma condição da interface $\mathrm{PF}$, o que explica que tenha um reflexo em PF: a contração [P+art], encontrada sempre que as condições fonológicas permitem.

Quanto ao licenciamento dos clíticos, a tradição gerativa tem assumido que são realizados em núcleos funcionais acima de VP, havendo variação translingüística quanto à categoria funcional relevante:

(12) $\left.\left[_{\mathrm{xP}}[c l[\mathrm{~F}]] \ldots\left[{ }_{\mathrm{VP}} \mathrm{V} \ldots\right]\right]\right]$

Nesse sentido, o clítico pode ser visto como a realização de traços phi em um núcleo funcional, o que pode ser comparado à contração [P+art], tal como analisada no presente estudo. Além disso, cabe indagar o que leva a categoria pronominal D a realizar-se na projeção funcional. Assumindo-se a linha de raciocínio desenvolvida nesse estudo, pode-se falar em um traço EPP, o que parece plausível, dado que esse traço tem sido analisado como uma condição da interface $\mathrm{PF}$, o que justifica que seja satisfeito por elementos definidos em termos de propriedades prosódicas, como os clíticos.

Retomando-se a correlação ilustrada na tabela 1, em que a presença da contração [P+art] implica a impossibilidade de deixar a preposição órfā, verificase que o contraste se mantém, se considerada a presença de clíticos no sistema pronominal e a contração [P+art], conforme ilustrado na tabela 3:

\begin{tabular}{ccc} 
& $+/-[\mathrm{P}+$ art $]$ & $+/$-clíticos \\
Românicas & - & + \\
Alemão & - & + \\
Holandês & - & + \\
Inglês & + & - \\
Escandinavas & + & - \\
\hline
\end{tabular}

Assim, pode-se dizer que a variação translingüística se refere à possibilidade de realizar traços phi em um dado núcleo, o que permite unificar clíticos e artigos em termos da propriedade de cliticização, nas línguas românicas. Um corolário dessa correlação é a presença de traços phi no artigo.

A comparação entre as tabelas 1 e 3 permite que se faça a correlação entre a presença de clíticos pronominais e a ocorrência de $P$ órfã. Em inglês, a perda de clíticos pronominais coincide com o surgimento das estruturas com $\mathrm{P}$ 
órfã. Igualmente, em línguas escandinavas, clíticos pronominais não são encontrados e $\mathrm{P}$ pode ficar órfã. Nas línguas românicas, no alemão e no holandês, verifica-se o padrão oposto: clíticos pronominais são encontrados e $P$ não pode ficar órfă.

Cabe ainda considerar a perda do clítico acusativo de $3^{\mathrm{a}}$ pessoa $\mathrm{p}$ no português do Brasil ( $\mathrm{PB}$ ). Note-se, porém, que esse aspecto não invalida as correlações realizadas no presente estudo, dado que clíticos de $1^{\mathrm{a}}$ pessoa (e de $2^{a}$ pessoa) são ainda encontrados no $\mathrm{PB}$. Naturalmente, há que se considerar que a presente análise apóia-se na discussão acerca do desenvolvimento de clíticos e artigos nas línguas românicas, a qual enfoca particularmente as formas de $3^{\mathrm{a}}$ pessoa. Entende-se, porém, que a sintaxe do pronome objeto de $3^{\mathrm{a}}$ pessoa no PB é um desenvolvimento posterior, tendo surgido no contexto de outras transformações.

Uma forma de analisar essa questão é considerar que as propriedades identificadas na categoria $\mathrm{D}$ (por exemplo, a presença de traços phi), em português e nas línguas românicas, são necessárias, mas não suficientes, para a manifestação das correlações formuladas. Em particular, é preciso haver as condições eliciadoras dos processos de cliticização sintática, as quais estão formuladas no presente estudo em termos da presença do traço EPP, na projeção PP e na categoria funcional relevante, acima de VP.

O fato de que em PB a perda dos clíticos atinge a 3p, mas não a $1 p$ (e a 2p) sugere uma situação de bifurcação no sistema gramatical. A situação de bifurcação do sistema gramatical, particularmente no que se refere às pessoas gramaticais, encontra paralelo, por exemplo, nos casos de ergatividade bifurcada, em línguas australianas. O exame dessa hipótese foge ao escopo do presente estudo, razão pela qual deixamos para investigação futura.

\section{Conclusão}

No presente estudo, examinou-se a correlação entre a sintaxe de clíticos e de artigos em português. Demonstrou-se que o fenômeno da contração entre a preposição e o artigo tem um correlato sintático, tendo sido analisado em termos de um processo de cliticização do artigo no núcleo preposicional, sempre que as condições morfofonológicas permitem. Essa análise permitiu formular um paralelo entre artigos e clíticos pronominais, corroborando uma relação que se manifesta no desenvolvimento diacrônico dessas categorias, bem com a idéia de lhes conferir um estatuto categorial idêntico, em termos da hipótese DP. 
O estudo, formulado no quadro teórico da gramática gerativa, em particular nos termos do programa minimalista de investigação lingüística, vem oferecer elementos para confirmar a hipótese de que a variação lingüística se manifesta nas propriedades de núcleos funcionais.

\section{RESUMO}

Examina-se a sintaxe dos artigos em português (e demais línguas românicas), demonstrando-se que a contração entre a preposição e o artigo [P+art] é a expressão morfofonológica da operação Agree, que licencia o sintagma determinante (DP) na posição de objeto da preposição, mediante a checagem de traços phi (pessoa, gênero, número). Argumenta-se que essa operação é realizada por movimento de núcleo, formando o núcleo complexo $[\mathrm{P}+\mathrm{D}]$ na sintaxe, o que explica que a preposição seja carreada obrigatoriamente nos deslocamentos de sintagmas interrogativos (QU) e impede o fenômeno da preposição órfã. Considerando-se que clíticos têm sido analisados como a realização de traços-phi em categorias funcionais, propõe-se identificar clíticos e artigos em termos dessa propriedade, conferindo-se ao Determinante nas línguas românicas o caráter de clítico sintático, uma propriedade sob variação entre as línguas.

Palavras-chaves: Clíticos, artigos, preposiçōes, caso.

\section{ABSTRACT}

The present study examines the syntax of articles in portuguese (and other romance languages). It is shown that the coalescence between the preposition and the article [ $\mathrm{P}+\mathrm{art}]$ is the morphophonological expression of the Agree operation, which licenses the determiner phrase (DP) in the object position of the preposition under phifeatures checking (person, gender, number). It is argued that this operation is realized under syntactic head movement, forming a complex head $[\mathrm{P}+\mathrm{D}]$, which in turn requires the preposition to be pied-piped in the movement of interrogative phrases (WH), blocking preposition stranding. Given that clitics have been analysed as the realization of phifeatures on functional heads, an identification between articles and clitics is proposed, 
SALLES, H. M. M. L. Aspectos da sintaxe de clíticos...

assigning a clitic status to Determiners in Romance, a property under variation crosslinguistically.

Key-words: clitics, articles, prepositions, case.

\section{REFERÊNCIAS}

BALTIN, M.; POSTAL, P. M. (1996). Remarks and Replies. Linguistic inquiry, n. 27, p. 127-145.

CARDINALETTI, A.; STARKE, M. (1994). The typology of structural deficiency: on the Three Grammatical Classes. No prelo.

CHOMSKY, N. (1995). The minimalist program. Cambridge. Mass: MIT Press. (1998) Minimalist inquiries. Cambridge; Mass: MIT Working Papers.

HELMANTEL, M. (1997). Aspect and adpositions: the Point of View of Dutch and German. Ms. University of Leiden.

HORNSTEIN, N.; WEINGERG, A. Case theory and preposition stranding. Linguistic inquiry, n. 12, p. 55-92, 1981.

KAYNE, R. (1984). Connectedness and Binary Branching. Dordrecht: Foris, 1984. p. 103-23. . (1994). The antisymmetry of syntax. Cambridge; Mass.: The MIT Press.

KOOPMAN, H. (1993). The structure of Dutch PPs. Ms. UCLA.

RADFORD, A. Syntactic theory and the structure of English. Cambridge: Cambridge University Press, 1997.

RIEMSDIJK, H. (1978). A case study in syntactic Markedness - the binding nature of prepositional phrases. Dordrecht: Foris.

RADFORD, A. (1997). Syntactic theory and the structure of English - a minimalist approach. Cambridge: Cambridge University Press.

SALLES, H. Prepositions and the syntax of complementation. 1997. Dissertation (Ph. D.) - University of Wales-Bangor. 

(2000). A sintaxe de pre- e posposições em línguas germânicas. Rio de Janeiro: Universidade Federal Fluminense. Comunicação ao Encontro Nacional da ANPOLL.

TARALlO, F. Relativization strategies in Brazilian Portuguese. Pennsylvania, 1983. Dissertation (Ph. D.) - University of Pennsylvania.

VINCENT, N. (1997). The Emergence of the D-system in Romance, In: VINCENT, N.; KEMENADE, V. (Orgs.). Parameters of morphosyntactic change. Cambridge: Cambridge University Press. p. 149-169. 